\title{
Topology optimised metallic bone plates produced by electron beam melting: a mechanical and biological study
}

\author{
Abdulsalam Abdulaziz Al-Tamimi ${ }^{1,2} \cdot$ Boyang Huang ${ }^{2} \cdot$ Cian Vyas $^{2} \cdot$ Miguel Hernandez $^{3} \cdot$ Chris Peach $^{2,4}$. \\ Paulo Bartolo ${ }^{2}$
}

Received: 19 March 2019 / Accepted: 9 May 2019 / Published online: 25 May 2019

(C) The Author(s) 2019

\begin{abstract}
Metallic bone plates are commonly used as a medical implant to treat bone fractures. The gold standard materials for these implants are biocompatible 316L stainless steel, cobalt chromium, titanium and its alloys (e.g. CoCrMo and Ti6Al4V). However, the main disadvantage of these implants is the material stiffness mismatch between the implant and bone. This mismatch may negatively affect the biological processes in bone healing. This paper investigates topology optimization to produce plates with reduced equivalent stiffness and the fabrication of optimised plate designs using an electron beam melting (EBM) system. Nonpost-processed EBM plates were assessed against commercially available bone fixation plates in terms of mechanical and biological characteristics. Results show that some redesigned produced plates present mechanical properties similar to the cortical bone and that there is no need to post-process the produced plates in order to establish a good biological bonding with the surrounding tissue.
\end{abstract}

Keywords Additive manufacturing · Bone fixation plates · Electron beam melting · Stress shielding · Topology optimization · Biocompatibility

Paulo Bartolo

paulojorge.dasilvabartolo@manchester.ac.uk

Abdulsalam Abdulaziz Al-Tamimi

Abdulsalam.altamimi@ postgrad.manchester.ac.uk

Boyang Huang

Boyang.huang@manchester.ac.uk

Cian Vyas

Cian.vyas@postgrad.manchester.ac.uk

Miguel Hernandez

Miguel.hernandez@postgrad.manchester.ac.uk

Chris Peach

Chris@shouldersandelbows.co.uk

1 Industrial Engineering Department, College of Engineering, King Saud University, Riyadh, Saudi Arabia

2 School of Mechanical, Aerospace and Civil Engineering, The University of Manchester, Manchester, UK

3 School of Materials, The University of Manchester, Manchester, UK

4 Manchester University Foundation Trust, Manchester, UK

\section{Introduction}

Bone is a highly vascular and specialised tissue responsible for maintaining the shape of the skeleton, protecting soft tissues, transmitting the force of muscular contraction during movement, serving as a reservoir for ions and contributes to the regulation of the extracellular matrix, blood cell production and blood $\mathrm{pH}$ regulation [1].

Bone is prone to traumatic injuries as well as diseases. In the case of minor fractures, bone heals and remodels with little detectable scarring. However, in the case of pathological and traumatic fractures, traumatic bone loss or primary tumour resection, bone is not able to heal itself [2-4]. Bone fractures that are displaced or unstable are frequently surgically treated with bone fixation implants such as internal fixation devices, external fixators and intramedullary pins. In the case of internal fixation devices, the locking compression plate (LCP) is widely used to treat various types of fractures due to its hybrid screw system containing two means of fixation techniques. This allows the application of absolute stability or relative stability leading to both primary healing and secondary healing [5]. Similar to other internal fixation plates (e.g. dynamic compression plate and periarticular locking plate 
system), LCP is made from an inert and biocompatible metal. The most commonly used metallic materials are titanium and its alloys, stainless steel, or cobalt chrome and its alloys [6, 7].

The role of the internal fixation plates is to stabilise the fractured bone during the union/healing process. After the fracture is healed, the implant is no longer required to stay in the body. Currently, around $30 \%$ of the metallic implants have to be surgically removed after the healing process [8]. However, this procedure presents significant risks of bone refracture and nerve damage. Bone refracture is due to the lack of density of the bone in the close vicinity of the implant due to the significant mechanical differences between bone and fixation plates. For example, the Young's modulus of Ti6Al4V is around $120 \mathrm{GPa}$ whilst the Young's modulus of trabecular bone ranges between 50 and $100 \mathrm{MPa}$ and between 15 and $25 \mathrm{GPa}$ in the case of cortical bone [7, 9, 10]. This Young's modulus mismatch results in a phenomenon named stress shielding which is usually associated with implant loosening and bone loss. Alternatively, the implant can be left in the body, but this option also presents problems such as risks of periprosthetic fracture due the stress risers at the cortical bone and implant junctions, corrosion, release of metal ions and the risk of allergic and potentially carcinogenic reactions $[11,12]$.

Several researchers also explored the use of novel additive manufacturing technologies to produce fully personalised metallic implants. A notable example was the fabrication of a metallic complex jaw implant coated with bioceramic and implanted in an 83-year-old lady. Partners in Belgium and the Netherlands (universities of Leuven and Hasselt, AM bureau LayerWise) designed the implant to guarantee good attachment of muscles and space for nerves and used a powder-bed fusion system to produce it [13]. Other research groups also explored powder-bed fusion techniques (selective laser melting and electron beam melting) to produce personalised metallic bone plates without any concerns regarding the stress shielding effect [14]. Very few studies addressed this problem by changing the plate design (e.g. plate thickness) to improve its performance through a trial and error approach [15]. A systematic approach is still required. This paper presents an integrated approach linking computer modelling, simulation and optimisation together with additive manufacturing to address this problem. The following research questions are addressed:

- Is it possible to use topology optimization to produce plates with reduced equivalent stiffness?

- Is it possible to automatically produce optimised plate designs using an electron beam system?

- Are the mechanical properties of the produced plates similar to the designed ones and similar to the cortical bone?

- Is it necessary to post-process the produced plates in order to establish a good biological bonding with the surrounding tissue?

\section{Initial bone plate design}

There are no standard dimensions (i.e. length, width and thickness) or number of screw holes for commercially available bone fixation plates. Different commercial companies are also commercialising plates of the same type (e.g. locking compression plates) with different dimensions. Commercial bone plates from the same company present the same width and thickness but different lengths. Therefore, the number of distinct topologies (geometry and number of holes) is high.

In this research, the DePuy Synthes narrow locking compression plate (DePuy Synthes, Synthes GmbH, Switzerland) was considered as the reference design. Plates containing four, six and eight holes, with $180 \mathrm{~mm}$ in length, $14 \mathrm{~mm}$ in width and $5 \mathrm{~mm}$ in thickness, were defined (see Table 1) and considered for redesigning.

\section{Computer modelling, simulation and optimisation}

Plates were initially designed using Solidworks (Dassault Systèmes, France). Optimisation was conducted using the Abaqus Topology Optimization Module (ATOM) software (Dassault Systèmes, France), and the Solid Isotropic Microstructure with Penalization (SIMP) method proposed by Bendsøe [16]. Mathematically topology optimization is described as follows [17]:

$\stackrel{\min }{-} \rho_{\mathrm{e}} C\left(\rho_{\mathrm{e}}\right)=f^{\mathrm{T}} \cdot u$

subject to

$$
\left\{\begin{array}{c}
\sum_{\mathrm{e}=1}^{N} \rho_{\mathrm{e}} v_{\mathrm{e}} \leq V^{*}, \\
\sum_{\mathrm{e}=1}^{\mathrm{N}} \rho_{\mathrm{e}}^{p} K_{\mathrm{e}} u=f, \\
0<\rho_{\mathrm{o}} \leq \rho_{\mathrm{e}} \leq 1,
\end{array}\right.
$$

where $C$ is the compliance, $f$ is the force vector, $K_{\mathrm{e}}$ is the element stiffness matrix, $u$ is the displacement vector, $V^{*}$ is the user-defined fraction volume, $p$ is the penalisation factor, $\rho_{\mathrm{e}}$ is the element density, $\rho_{\mathrm{o}}$ is the initial density and $v_{\mathrm{e}}$ is the volume of each element.

The iterative process to achieve the optimal design starts with the definition of a design domain, $\Omega$, discretised into a set of elements with specific density $(\rho)$ and Young's modulus $(E)$ values. Loading and boundary conditions are imposed, generating stresses and strains at each element, determining the corresponding sensitivity, i.e. the element that will have their density updated. Filtering techniques are implemented to restrict the optimisation from common disadvantages such as checkerboarding. The density is distributed along the design domain and updated after each iteration toward optimality according to the derivative of Eq. (1), considering for each element the value of $\rho=1$ for full element stiffness and $\rho=0$ for a void. The density update process is repeated until reaching the optimal solution. 
Table 1 The design domain of the bone plates

Plate Number
name of holes

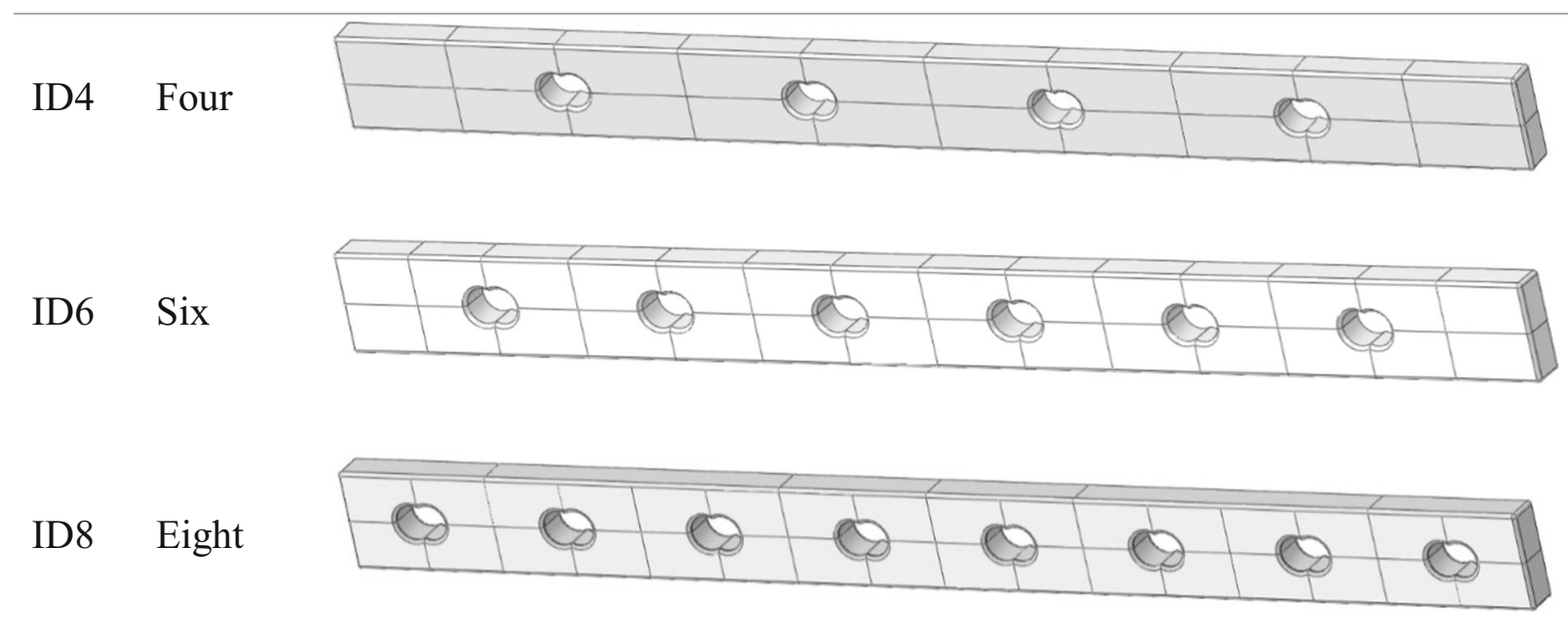

Even though topology optimization is a load magnitude independent process, a post-operative case of a $70-\mathrm{kg}$ patient was considered. Post-operation, patients suffering from a fractured tibia walk with crutches and their gait induces an overall load on the legs equivalent to $10 \%$ of the bodyweight [18]. Therefore, we assume a static compression force of $70 \mathrm{~N}$ applied on both far-end sides of the bone plate. Screw holes were considered a frozen design region. Ti6Al4V (Young's modulus of $120 \mathrm{GPa}$ and 0.3 Poisson's ratio) was considered as the bone plates' material. Different volume reductions $(25,45$ and $75 \%)$ were considered and a mesh of approximately 50,000 8-node linear hexahedral elements was used for all considered geometries.

The redesigned plates were computationally assessed considering a static mechanical tensile test to determine their equivalent stiffness. In this case, a longitudinal force $\left(F_{x x}\right)$ in the $x$-axis direction is applied to one side of the plate constraining the movement of the opposite side. Following a previously reported procedure [19], the equivalent stiffness of the designed plates can be determined as follows:

$K=\frac{R F_{x x}}{U_{x x}}$

where $K$ is the structural stiffness, $R F_{x x}$ is the reaction force on the constraint face and $U_{x x}$ is the displacement.

\section{Fabrication process}

Bone fixation plates were prepared (e.g. part orientation, design of support structures and position in the building platform) using the software Magics (Materialise, Belgium) and exported as STL files to the Build Assembler software where the models were sliced and uploaded to the machine. Support structures were designed considering part stability and to reduce both thermal stresses and warping. The EBM Arcam A2 model (Arcam, Sweden) was used for producing the plates. Its schematic configuration is shown in Fig. 1a. The machine consists on an electron beam emitted from a hot tungsten filament, operates at $60 \mathrm{kV}$ under vacuum pressure of $2.0 \times 10-3 \mathrm{mBa}$, scanning speed of $4530 \mathrm{~mm} / \mathrm{s}$, beam focus offset of $3 \mathrm{~mA}$, line offset of $0.1 \mathrm{~mm}$ and layer thickness of $50 \mu \mathrm{m}$. The substrate plate temperature was kept at $\sim 600{ }^{\circ} \mathrm{C}$ and the build temperature was defined to be $~$ $750{ }^{\circ} \mathrm{C}$. Parts were produced using standard Ti6Al4V powder supplied by the machine manufacturer. The powder material consists of spherical gas atomised particles with a size raging between 45 and $100 \mu \mathrm{m}$ (see Fig. 1b), composed of $6.04 \%$ of aluminium, $4.05 \%$ of vanadium, $0.013 \%$ of carbon, $0.0107 \%$ of iron, $0.13 \%$ of oxygen and balanced titanium.

The EBM fabrication process initiates with the entire titanium powder being scanned and preheated to $750{ }^{\circ} \mathrm{C}(80 \%$ of its melting temperature) with a low beam current of approximately $0.2 \mathrm{~mA}$ and high scanning speed up to $8000 \mathrm{~m} / \mathrm{s}$ to minimise residual stresses. After fabrication, the powder recovery system was used to remove all trapped powder through blasting a stream of high-pressure air and the support structures were removed using pliers. Parts were not submitted to any post-processing operation or thermal treatment. 


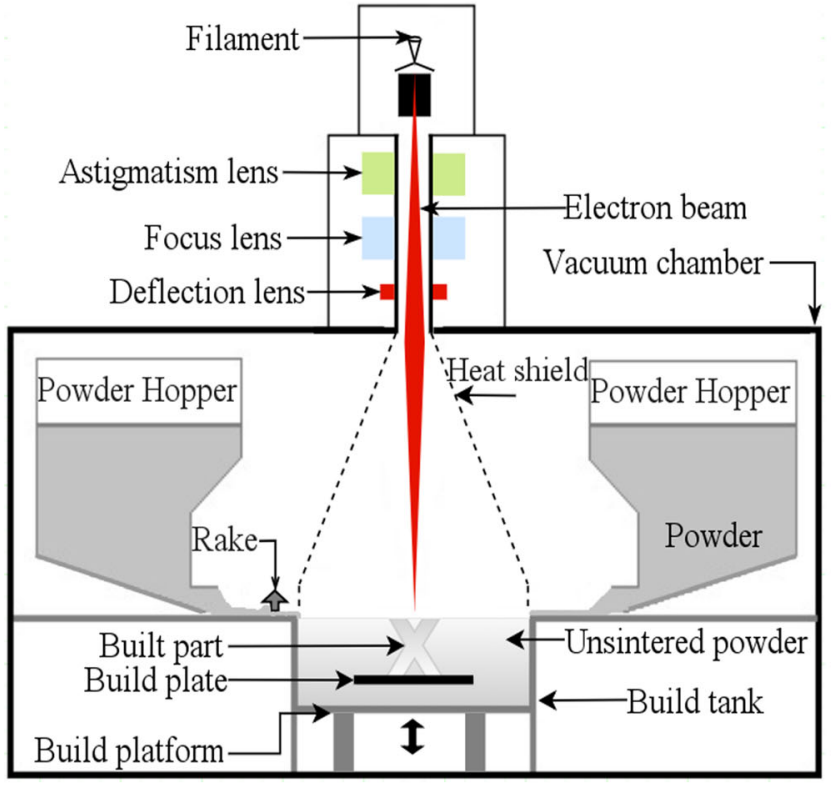

a)

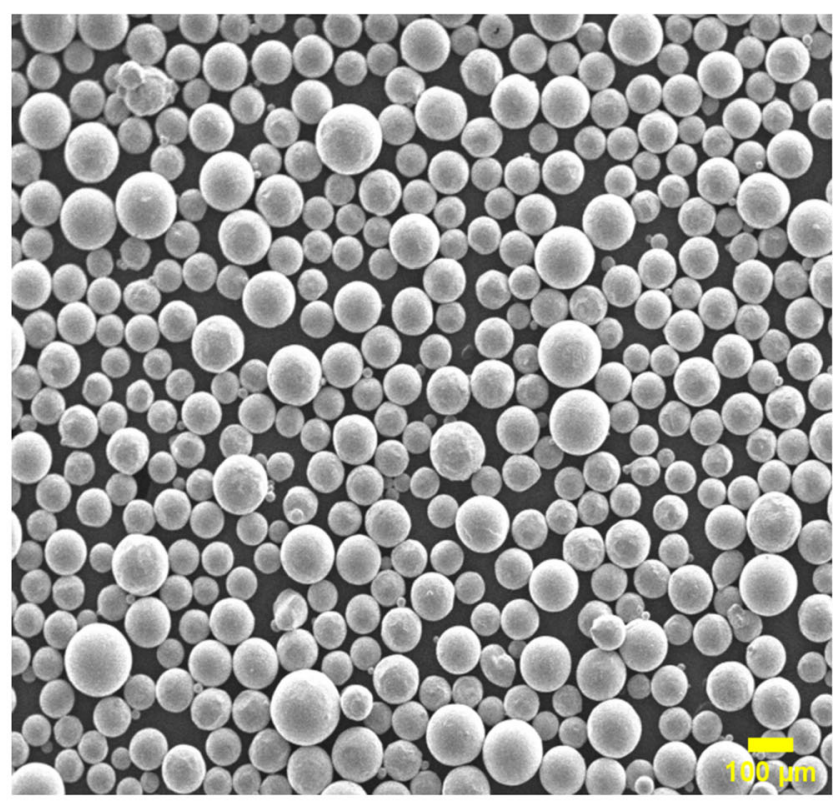

b)

Fig. 1 a The Arcam A2 EBM system schematic. b Scanning electron microscopy of the Ti6A14V powder

\section{Characterisation of produced plates}

\subsection{Mechanical testing}

Bone plates were mechanically assessed against the mechanical properties of cortical bone and compared to four commercially available titanium Depuy Synthes LCP 4.5/5.0 narrow bone plates with different screw holes (ten, nine, eight and six holes) purchased from DePuy Synthes (DePuy Synthes, Synthes $\mathrm{GmbH}$, Switzerland). The test is a displacement controlled quasi-static tension using the Instron ${ }^{8} 8862$ system (Instron, MA, USA) with a maximum force of $100 \mathrm{kN}$. All tests were performed at room temperature until plate failure. Failure is determined by either plate crack, breakage or extreme plastic deformation, whichever occurred first. The test considered a 0.5 $\mathrm{mm} / \mathrm{min}$ displacement rate. Strains and displacements were measured using a standard straight profile knife edged extensometer (2630-106, Instron, USA). Tests were performed in duplicate. Force and displacement histories were documented at a sampling rate of $10 \mathrm{~Hz}$, and the mean slope of the curve (i.e. stiffness) measured. The equivalent Young's modulus was obtained through the following procedure:

i) From the tensile test, and considering the linear elastic region, the following correlation between applied force $(F)$ and associated displacement $(\delta)$ determined by the extensometer can be established as follows:

$F=\kappa \delta$

where $\kappa$ is the stiffness. ii) Knowing the cross-section area and the initial length of each plate Eq. (3) can be transformed into

$\sigma=E \varepsilon$

where $\sigma$ is the stress, $\varepsilon$ is the strain and $E$ is the equivalent Young's modulus determined from the slope of the stressstrain curve. The yield stress was calculated by measuring the slope of the stress-strain curve from a $0.2 \%$ strain offset.

\subsection{Surface roughness}

Surface roughness was determined using a coaxial laser confocal microscope (Keyence, VK-X200, Japan) by scanning a zone of $500 \times 750 \mu \mathrm{m}^{2}$. The arithmetic average of the surface roughness, $\mathrm{Ra}$, and the average arithmetic height of the surface, $\mathrm{Sa}$, of both produced EBM plates and commercial plates were calculated considering 10 measurements with an area of $100 \times 100 \mu \mathrm{m}^{2}$ over a length of $500 \mu \mathrm{m}$ using the VK Analyzer 3.3 software (Keyence, Japan).

\subsection{Hardness}

Hardness was measured using the Vickers hardness (HV) tester-Armstrong Pedestal considering a normal load of $10 \mathrm{kgf}$ applied for $12 \mathrm{~s}$ as shown in Fig. 2a. Previously, the surface of the EBM bone plate was prepared using silicon carbide paper with a grid of 400, 800, 1200 and 2400 grits and polished with $1-\mu \mathrm{m}$ diamond particle paste. A total of 5 indentations were taken as shown in Fig. 2b: measurements 1, 


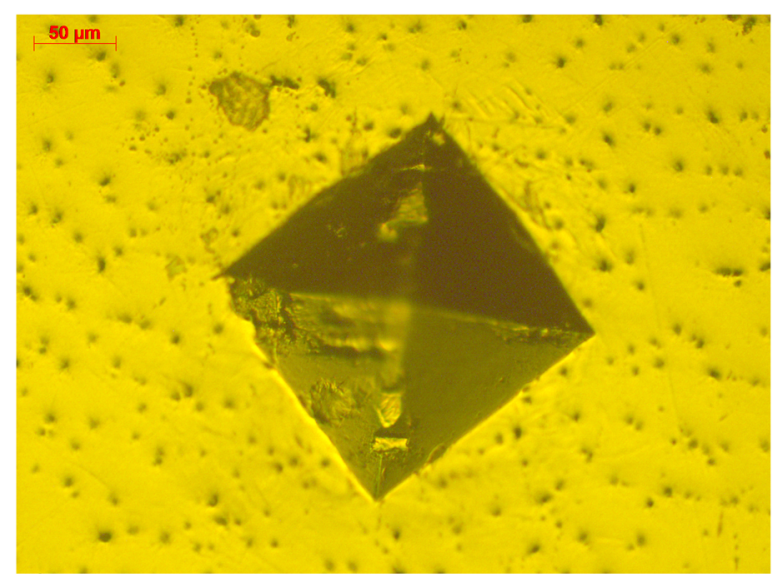

a)

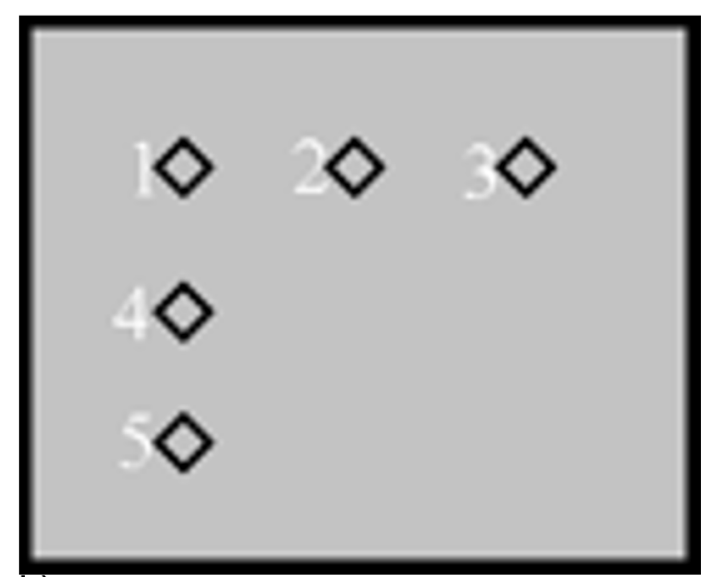

b)

Fig. 2 Surface hardness measurement. a Hardness indentation on the EBM bone plate sample. b Indentation measurements

4 and 5 along the $y$-axis and measurements 1,2 and 3 along the $x$-axis. The Vickers hardness was calculated replacing the average length of the diagonal, $d$, measured by optical microscopy from all the indentations in millimetres according to the following equation [20]:

$H v=\frac{18.55}{d_{2}}$

where $d_{2}$ is the arithmetic mean of the diagonals.

\subsection{Morphological characterisation}

The morphology of the EBM plates was investigated using scanning electron microscopy (SEM) with a Hitachi S300N microscope (Hitachi, Japan), using an accelerating voltage of $15.0 \mathrm{kV}$.

\subsection{In vitro biological testing}

Biological tests were conducted to understand the impact of the surface characteristics of the EBM plates and to investigate the potential need for any post-process in order to establish a good biological bonding with the surrounding tissue. A commercial plate was used as a reference.

\subsubsection{Sample preparation}

EBM and commercial bone plates were cut into samples to fit a 12-well plate using an electron discharge machine. Samples were sterilised by sonication whilst the samples were immersed within $80 \%$ ethanol for $30 \mathrm{~min}$, rinsed with distilled water and then autoclaved for $30 \mathrm{~min}$ at $121^{\circ} \mathrm{C}$.

\subsubsection{Cell culture and seeding}

In vitro tests were performed using human osteosarcoma cells Saos-2 (ATCC® HTB-85 ${ }^{\mathrm{TM}}$ ) (ATCC, Manassas, VA, USA).
Cells were cultured in T75 tissue culture flasks (SigmaAldrich, Dorset, UK) with McCoy's 5A Medium (ATCC® 30-2007TM) (ATCC, Manassas, Virginia, USA) based media containing $15 \%$ foetal bovine serum, supplemented with penicillin and streptomycin (1\%) until 80\% confluence and harvested using $0.05 \%$ trypsin-EDTA solution (Thermo Fischer Scientific, Waltham, MA, USA). Cells were seeded on the samples at a density of $5 \times 10^{\wedge} 4$ cells in $200 \mu \mathrm{L}$ of media per sample, and the cell-seeded samples incubated at standard conditions $\left(37{ }^{\circ} \mathrm{C}, 5 \% \mathrm{CO} 2\right.$ and $95 \%$ humidity) for $3 \mathrm{~h}$ to allow cell attachment, before the addition of $2 \mathrm{~mL}$ fresh media. Seeded samples were transferred into a new well plate after $24 \mathrm{~h}$. Cell culture media was changed every 3 days.

\subsubsection{Cell viability and morphology}

EBM and commercial samples were cultured up to 14 days to assess cell morphology and attachment through SEM. Samples were fixed with a $3 \%$ glutaraldehyde solution (Sigma-Aldrich, UK) for $30 \mathrm{~min}$ at room temperature, rinsed twice with phosphate-buffered saline (PBS) solution, dehydrated with a graded ethanol series $(50 \%, 60 \% 70 \%$, $80 \%, 90 \%$ and $100 \%$ (twice)), in 50:50 ethanol/ hexamethyldisilazane (HMDS, Sigma-Aldrich, Dorset, UK) and then in 100\% HMDS, for 15 min at each step, and allowed to evaporate overnight to remove HMDS.

Laser confocal microscopy was employed to examine cell viability through a Live/Dead stain kit (Thermo Fischer Scientific, Waltham, MA, USA) for days 4 and 14. The Live/Dead staining solution was prepared according to manufacturer's instruction. Briefly, a $4 \mu \mathrm{m}$ M EtHD-1 and of $2 \mu \mathrm{m} \mathrm{M}$ calcein AM working solution was prepared in PBS. The samples were washed with PBS prior to the addition of the staining solution and incubated for $45 \mathrm{~min}$ at room temperature. Cell viability images were obtained using an inverted Leica TCS SP5 confocal microscope (Leica Microsystems, Germany). 


\subsection{Statistical analysis}

The statistical analysis was performed using Minitab 18 software (PA, USA) considering one-way analysis of variance (ANOVA) with Tukey test. Differences were considered statistically significant at $p<0.05$.

\section{Results}

\subsection{Topology optimization and produced bone plates}

For the three different plate designs (four, six and eight holes), nine designs were obtained as shown in Fig. 3. The EBM produced bone plate after support structure removal are shown
Fig. 4 EBM-produced bone plates. Four-hole designs considering (a) $75 \%$ of volume reduction, (b) $55 \%$ of volume reduction, (c) $25 \%$ of volume reduction. Six-hole designs considering (d) $75 \%$ of volume reduction, (e) $55 \%$ of volume reduction, (f) $25 \%$ of volume reduction. Eight-hole designs considering (g) $75 \%$ of volume reduction, (h) $55 \%$ of volume reduction and (i) $25 \%$ of volume reduction. Initial designs considering (j) four holes, (k) six holes and (l) eight holes

in Fig. 4. Parts were not submitted to any post-processing operation or thermal treatment.

\subsection{Surface roughness}

Surface roughness of the EBM plates are presented in Fig. 5. Results showed arithmetic average of the surface roughness, $\mathrm{Ra}$ of $19.15 \pm 4.94 \mu \mathrm{m}$ and average arithmetic height of the surface, Sa of $12.42 \pm 1.11 \mu \mathrm{m}$ for the EBM plates, whereas
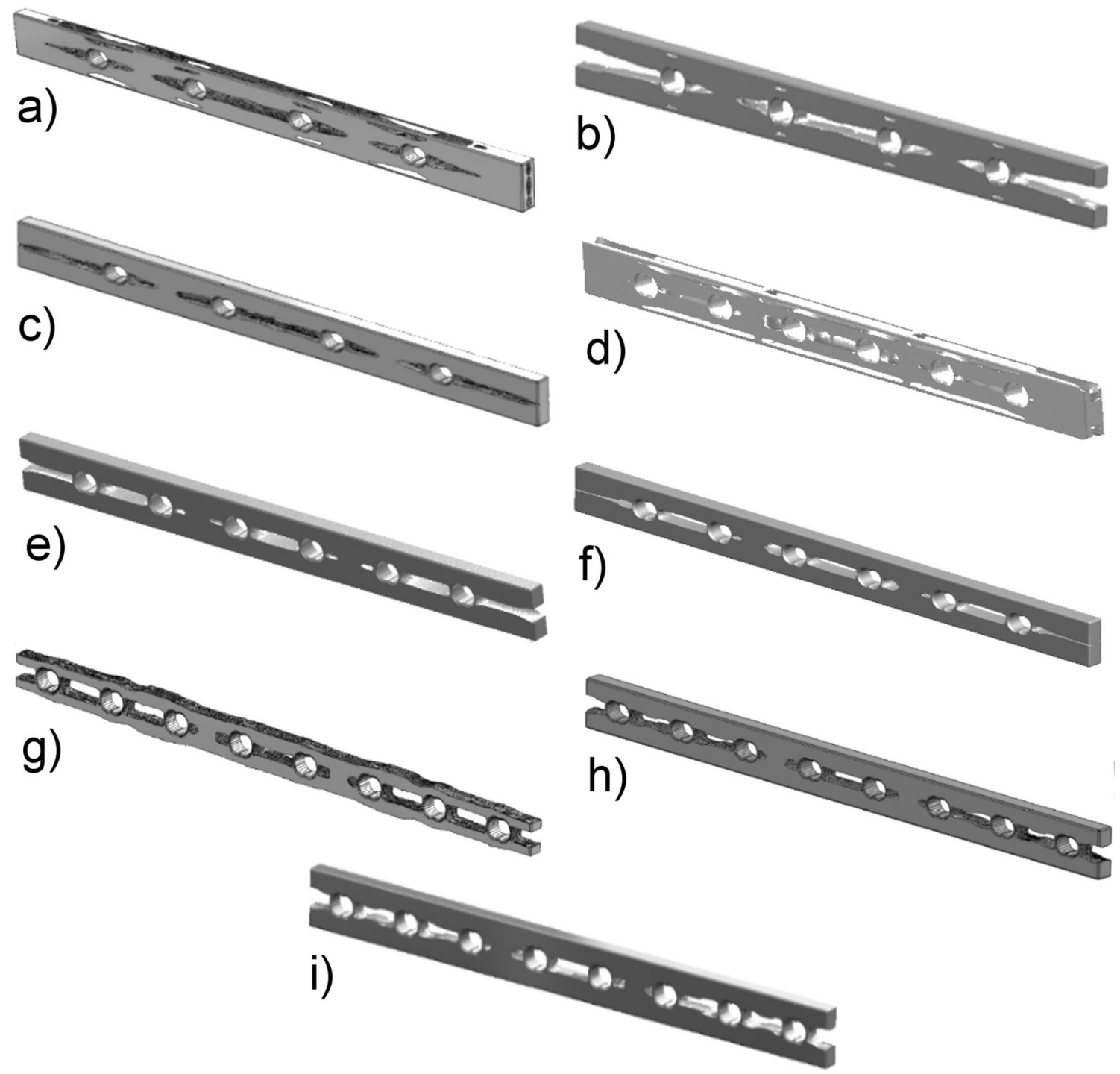

Fig. 3 Topology optimised plates. Four-hole plates considering a) $75 \%$ volume reduction, b) $45 \%$ volume reduction and c) $25 \%$ volume reduction; Six-hole plates considering d) $75 \%$ volume reduction, e)
$45 \%$ volume reduction, f) $25 \%$ volume reduction; Eight-hole plates considering g) $75 \%$ volume reduction, h) $45 \%$ volume reduction and i) $25 \%$ volume reduction 

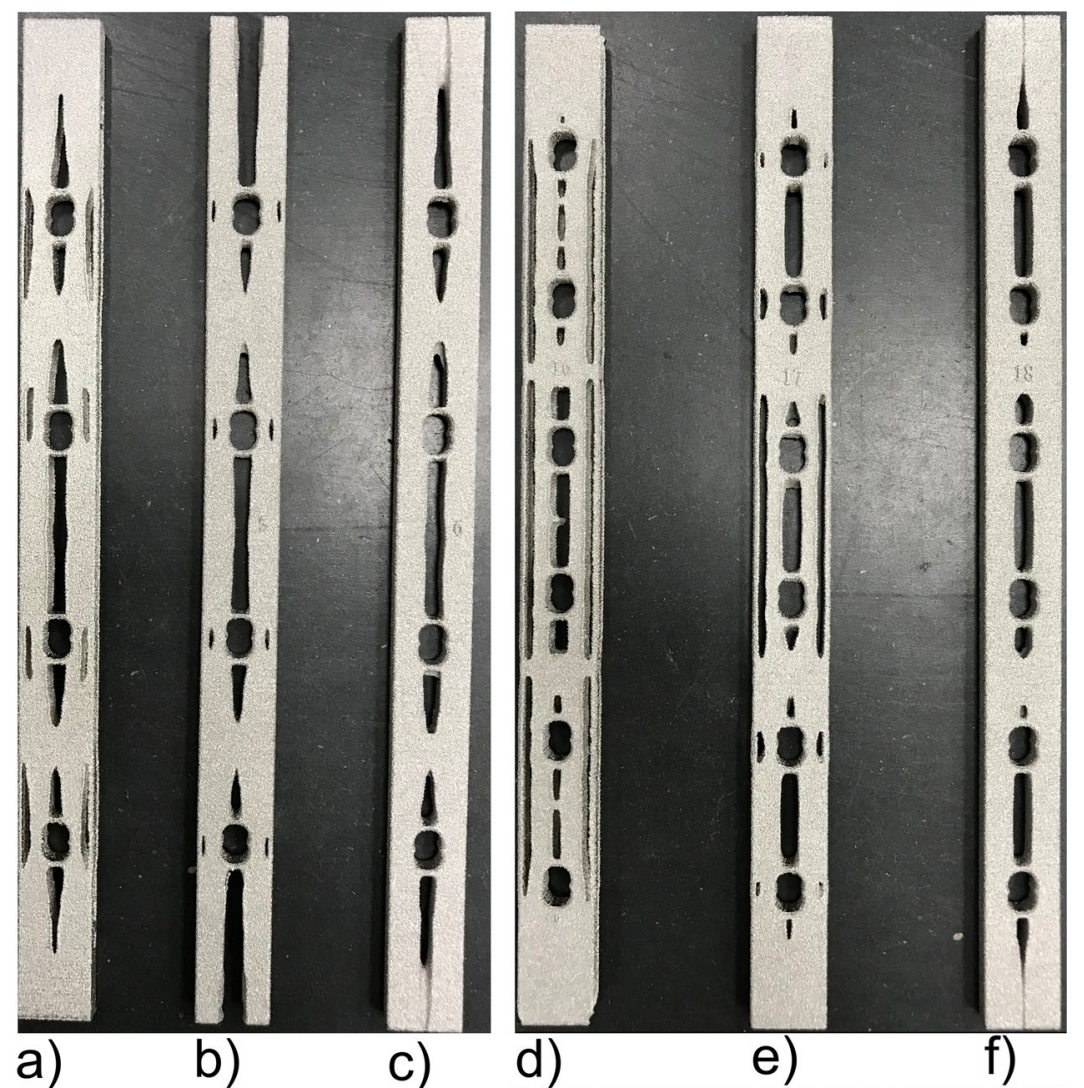

a)

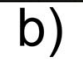

c)
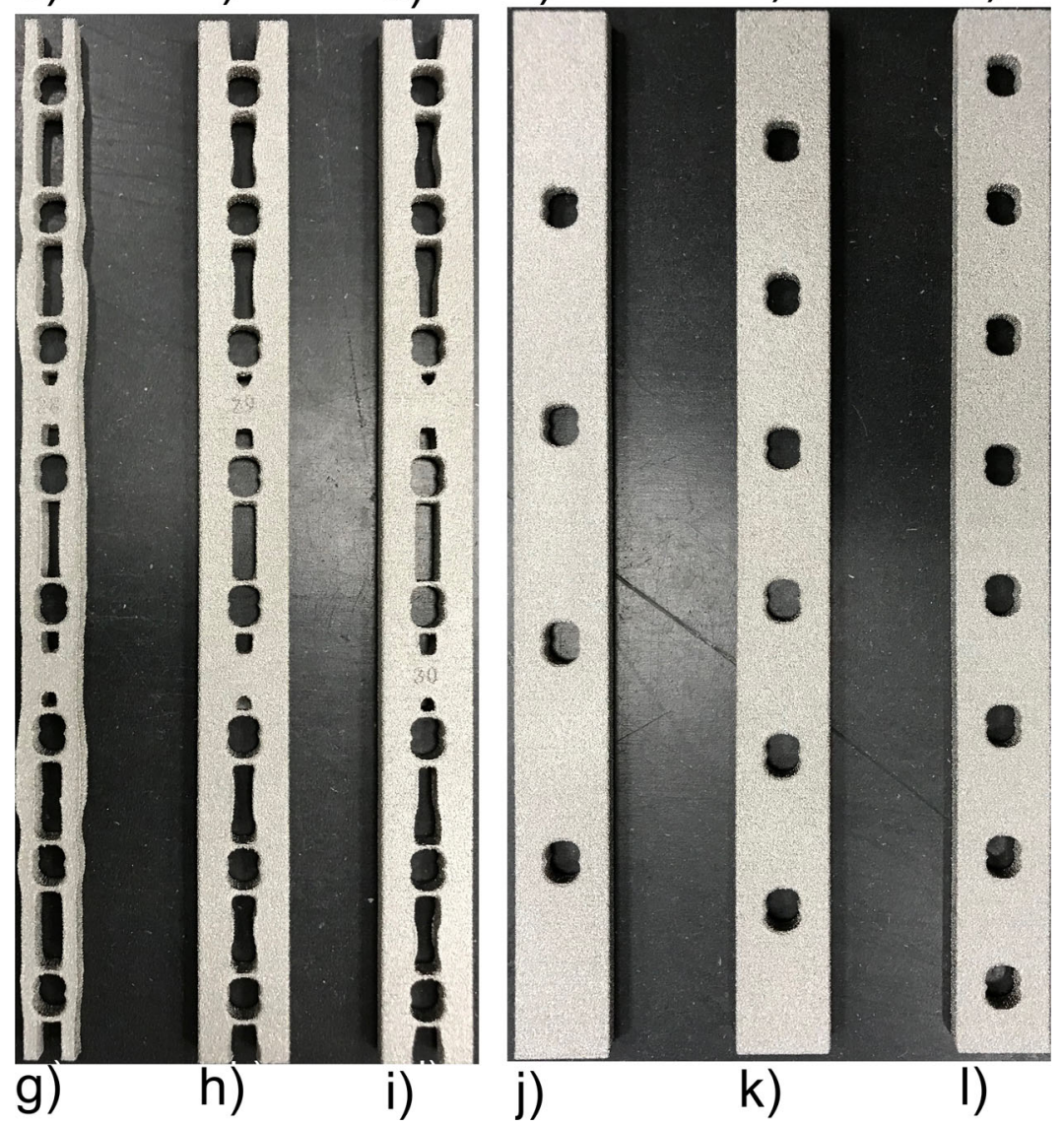
Fig. 5 a Surface of EBMproduced bone plate and $\mathbf{b}$ the surface roughness height across a line of the EBM surface
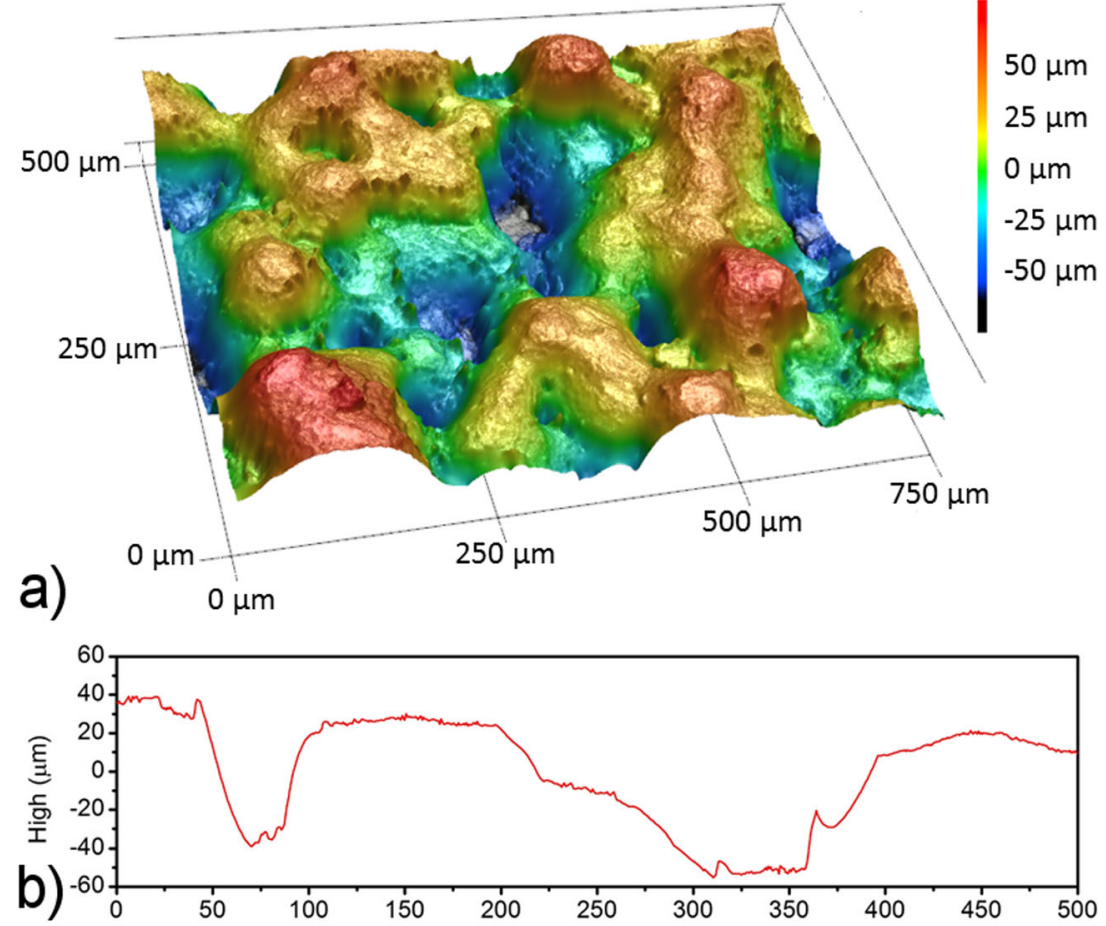

the commercial plates presented an average Ra of $0.37 \pm$ $0.03 \mu \mathrm{m}$ and $\mathrm{Sa}$ of $0.42 \pm 0.03 \mu \mathrm{m}$. Significant difference was observed $(p<0.05)$ between the samples for both $\mathrm{Ra}$ and $\mathrm{Sa}$.

\subsection{Hardness}

EBM-produced plates presented a high hardness compared to commercial plates. Results showed that the EBM plates mean hardness is $326.9 \mathrm{HV} 10 \pm 3.35$ and the mean hardness of the commercial plates is $275.98 \mathrm{HV} 10 \pm 7.75$. The hardness between the samples showed significant difference $(p<0.05)$.

\subsection{Tensile tests}

A comparison between experimental and numerically predicted tensile results are presented in Figs. 6, 7 and 8. A good approximation was obtained with differences not higher than $7 \%$.

The highest equivalent stiffness values were observed for the initial designs. Results also show high values of stiffness in plates containing a smaller number of holes $(293,810 \mathrm{~N} / \mathrm{mm}$ for four-hole plate, $242,634 \mathrm{~N} / \mathrm{mm}$ for six-hole plate and $226,132 \mathrm{~N} / \mathrm{mm}$ for eight-hole plate). Moreover, stiffness decreases by increasing volume reduction $(228,050 \mathrm{~N} / \mathrm{mm}$ for four-hole plate, $228,418 \mathrm{~N} / \mathrm{mm}$ for six-hole plate and $216,226 \mathrm{~N} / \mathrm{mm}$ for eight-hole plate and $25 \%$ of volume reduction; $152,648 \mathrm{~N} / \mathrm{mm}$ for four-hole plate, $118,970 \mathrm{~N} / \mathrm{mm}$ for six-hole plate, $216,147 \mathrm{~N} / \mathrm{mm}$ for eight-hole plate and $45 \%$ of volume reduction; $103,674 \mathrm{~N} / \mathrm{mm}$ for four-hole plate,
$52,011 \mathrm{~N} / \mathrm{mm}$ for six-hole plate, $55,824 \mathrm{~N} / \mathrm{mm}$ for eighthole plate and $75 \%$ of volume reduction).

A comparison of the equivalent Young's modulus values of all considered plates is provided in Fig. 9. Results show a decrease in the equivalent Young's modulus in the optimised plates. However, optimised plates considering $25 \%$ of volume reduction are three times stiffer than the cortical bone. The commercial plates resulted in an equivalent Young's modulus of around $40 \mathrm{GPa}$. Optimised six- and eight-hole plates considering $75 \%$ of volume reduction present values within the cortical bone region.

Table 2 presents the yield stress values from the tensile tests for all considered plates. In the case of commercially available plates, it was considered the maximum value between the four commercial plates investigated in this study. The yield stress values of the initial plates, four-hole $25 \%$ and $45 \%$ volume reduction and eight-hole $25 \%$ volume reduction are 1.5 to 3 times higher than the commercial plates, whilst the four-hole $75 \%$ volume reduction and six-hole $25 \%$ volume reduction plate showed approximately similar values. The two optimised bone plates that resulted with similar cortical bone modulus, the $75 \%$ volume reduction for the six- and eighthole bone plates, resulted in around half of the yield of the commercial plates and the maximum force reached before yield was around $4191 \mathrm{~N}$ and $5481 \mathrm{~N}$, respectively. The equivalent stiffness of the four-hole plates $(75 \%, 45 \%$ and $25 \%$ volume reductions) were significantly different $(p<0.05)$ than the four-hole initial plates. Six-hole plates $(75 \%$ and $45 \%$ volume reductions) showed significant difference between the six-hole initial plate with no significance when comparing 


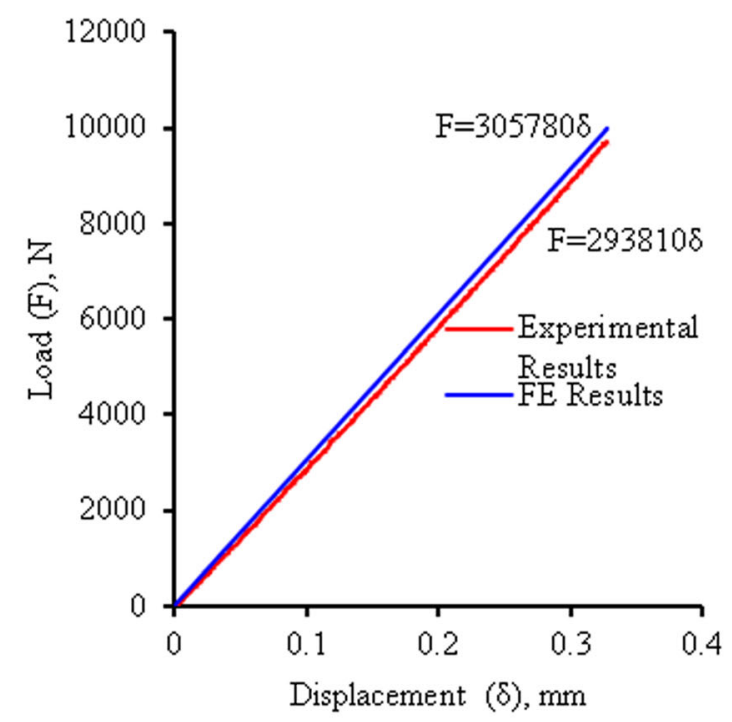

a)

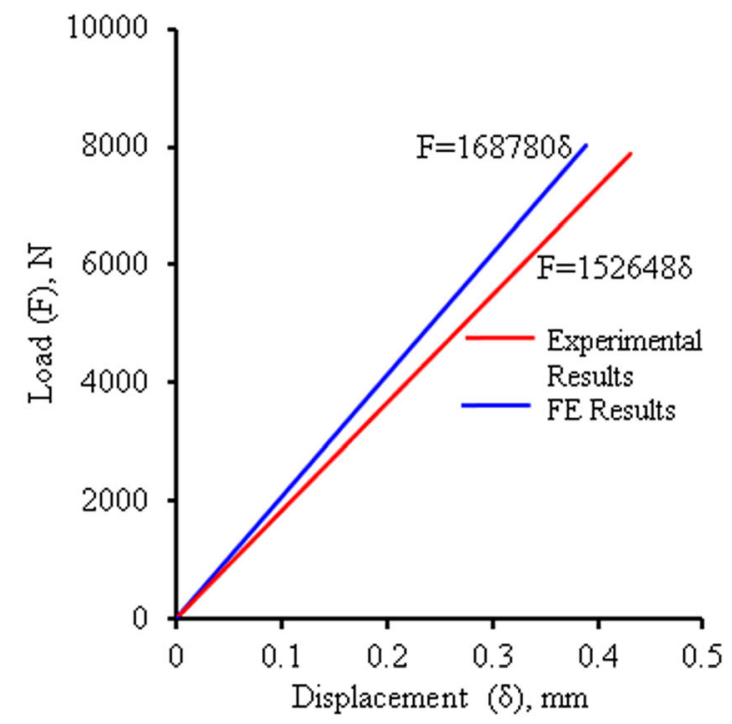

c)

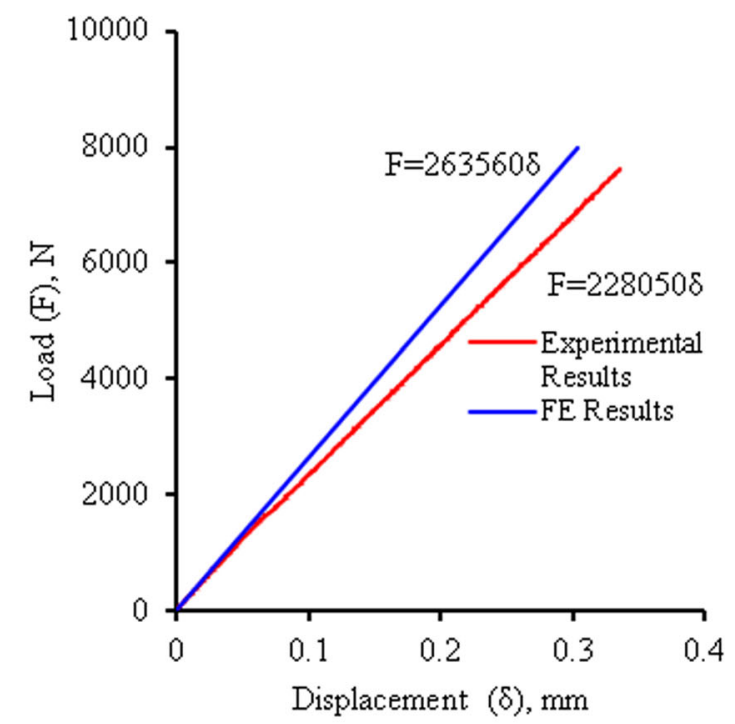

b)

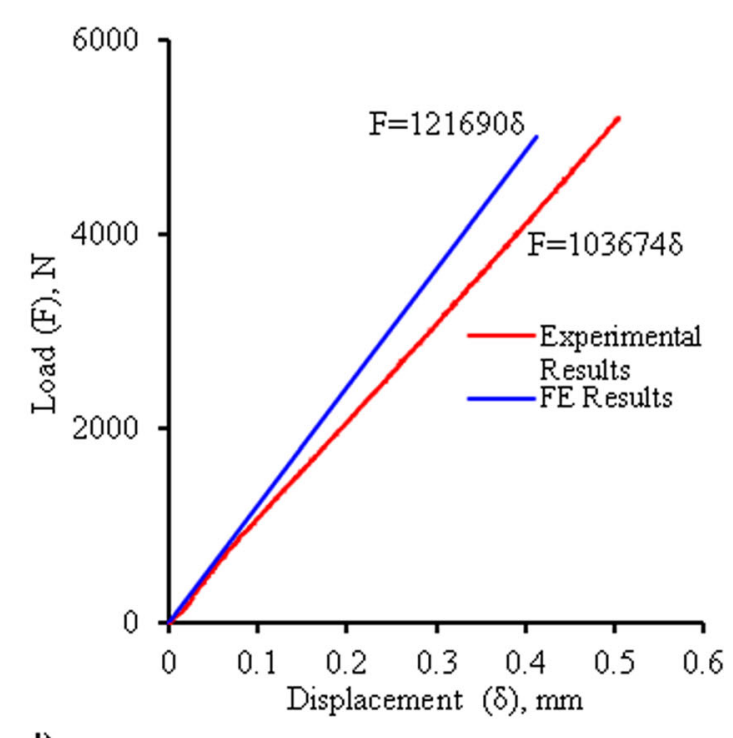

Fig. 6 Four-hole bone plates; a initial design, b 25\% reduction, c 45\% reduction and d $75 \%$ reduction

with the $25 \%$ volume reduction. Similar, significant difference was observed in the eight-hole plates. In terms of the equivalent Young's modulus, the four-hole $45 \%$ and $75 \%$ volume reduction, six-hole $75 \%$ volume reduction and eight-hole $45 \%$ and $75 \%$ volume reduction plates were significantly different $(p<0.05)$ comparing with the commercial plates. Similarly, the EBM (six-hole bone plates and $45 \%$ and $75 \%$ of volume reduction and eight-hole plates with $75 \%$ of volume reduction) presented significant lower yield stress than commercial plates $(p<0.05)$.

\subsection{Cell morphology and viability}

SEM images of the surface of both EBM and commercial plates are shown in Fig. 10a and b, respectively. The cell- seeded EBM plates after days 7 and 14 are shown in Fig. 10c and e, respectively, whilst cells seeded on commercial plates after days 7 and 14 are presented in Fig. 10d and f, respectively. Cell viability results are presented in Fig. 11 for both EBM and commercial plates after days 4 and 14 of cell seeding. Results show that cells are proliferating and are viable on the EBM plates whilst in the case of commercial plates, fewer cells attached with a higher number of dead cells.

\section{Discussion}

The topology optimization method is based on the material redistribution, eventually leading to a material reduction whilst optimising stiffness. As also previously reported, 


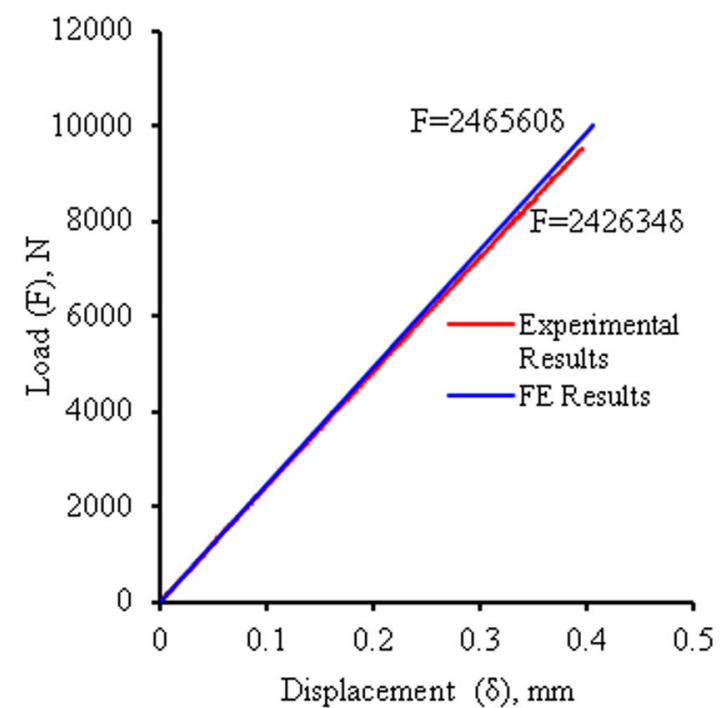

a)

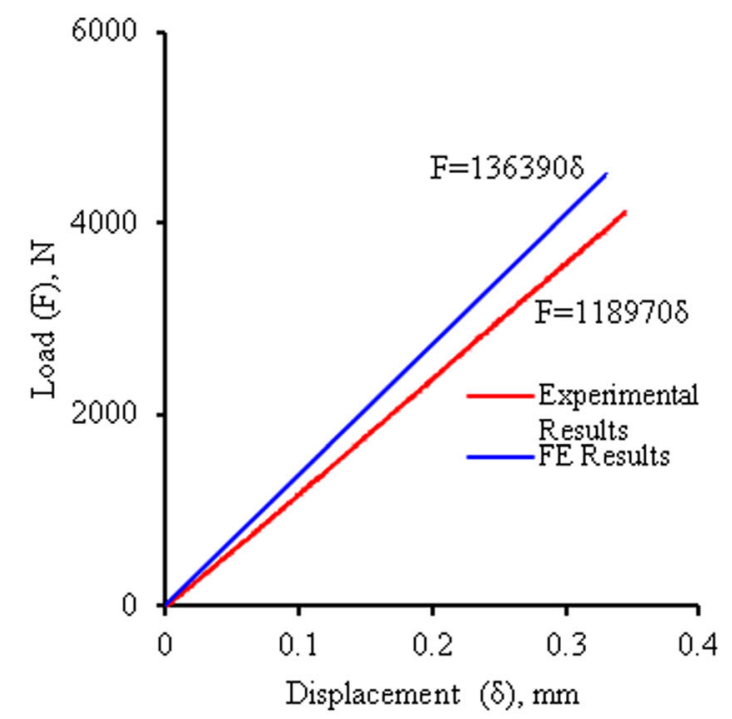

c)

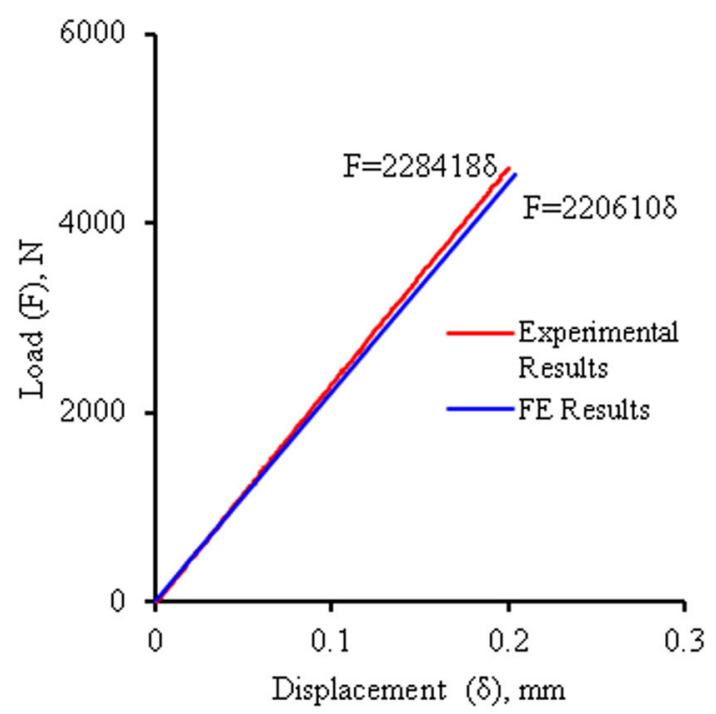

b)

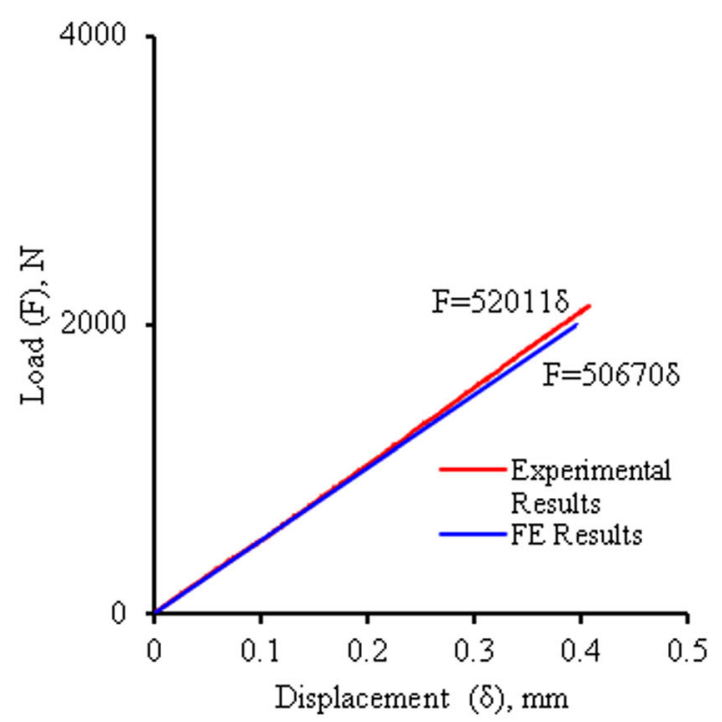

d)

Fig. 7 Six-hole bone plates; a initial design, b 25\% reduction, c $45 \%$ reduction and d $75 \%$ reduction

topology optimization can be used to create lightweight structures capable of keeping satisfactory mechanical performance $[21,22]$. By imposing high volume reduction, the effect of material removal becomes the significant contributing factor to an overall reduction in the stiffness of the plates. This was previously reported by the authors with $2 \mathrm{D}$ designed plates [23]. Different volume reductions were considered (25\%, 45\% and $75 \%$ ) but the obtained volume reduction was not always exactly the same as the imposed value. In the case of eighthole bone plates and imposed volume reductions of $25 \%$ and $45 \%$, no significant differences were observed on the optimised shapes in terms of equivalent stiffness as the optimisation procedure stopped at relatively similar volume reductions. This is due to the fact that the optimisation procedure stops once it reaches a local optimal value, which is not necessarily the global one. It can also be explained by Eq. 1a, which shows that the optimisation process approximates to the user-defined volume, and to the fact that the optimisation process is mesh-dependent. However, the effect of the mesh on the topology optimization is not considered here. An automatic mesh generation procedure was considered.

The function of a bone plate is to resist the stresses occurring in the physiological environment whilst stabilising the fractured bone. Therefore, avoiding mechanical failure as well as plastic deformation is critical. In this research, both the elastic and plastic deformations were considered. The elastic linear region was analysed to measure both the equivalent stiffness and equivalent Young's modulus. Equivalent stiffness values were used to characterise each family of bone plates (four, six and eight holes). Results show, for all cases, 


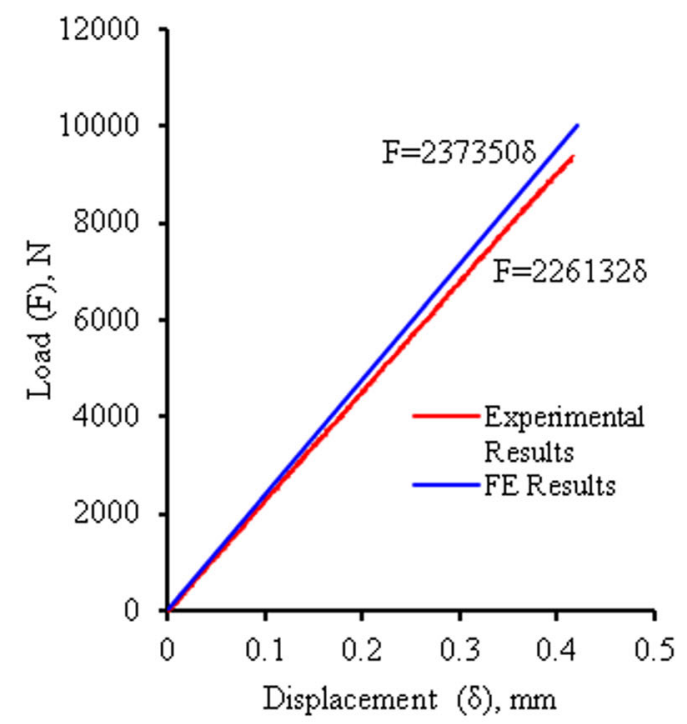

a)

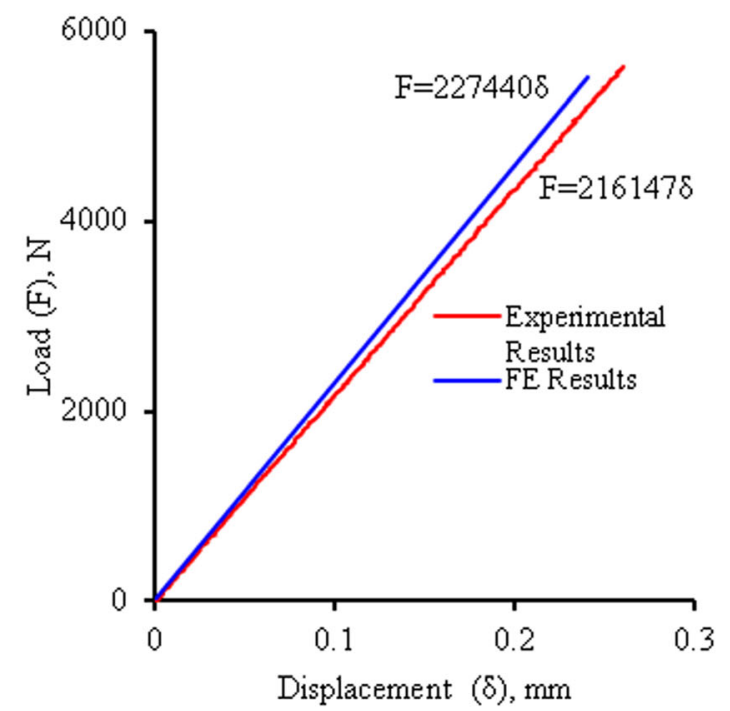

c)

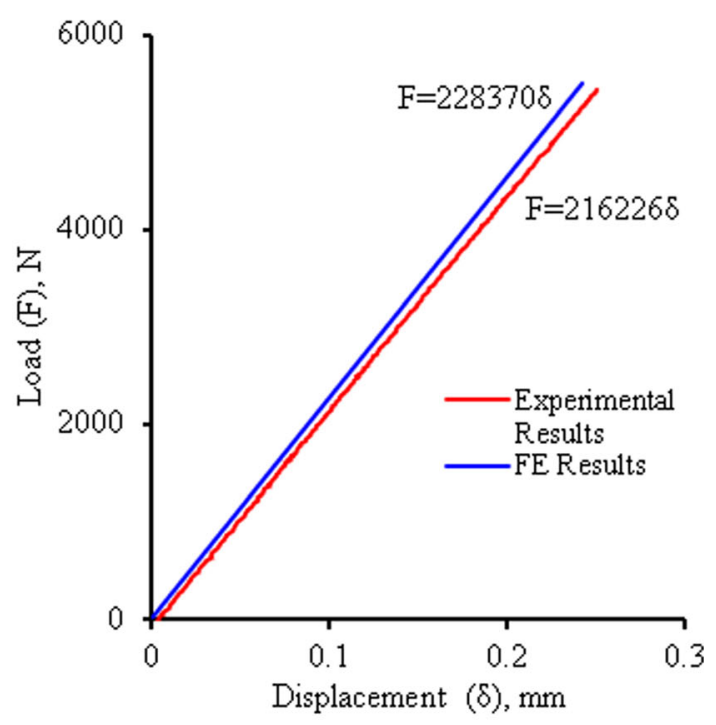

b)

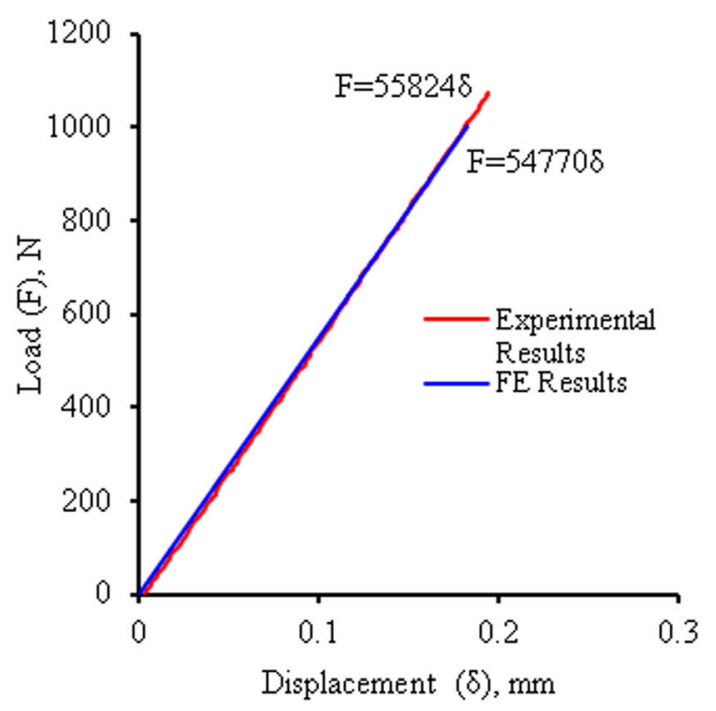

d)

Fig. 8 Eight-hole bone plates; a initial design, b 25\% reduction, c 45\% reduction and d $75 \%$ reduction

a reduction on the equivalent stiffness by increasing the volume reduction. A good approximation between numerical and experimental results was also obtained, showing that the computational tools considered in this research represent a viable approach to design and simulate their behaviour before expensive fabrication and experimental steps. Results also show that topology optimization is a viable tool to redesign bone plates, reducing their equivalent stiffness and consequently the stress shielding effect. The equivalent Young's modulus was used to position the mechanical properties of produced plates and commercial ones against cortical bone. Initial designed plates present higher equivalent Young's modulus values than commercial plates. These differences are reduced through topology optimization. Although as mentioned earlier, taking into consideration that the dimensions of the bone plates defer from one another, the EBM plates containing six holes $(45 \%$ of volume reduction) and four holes (75\% of volume reduction) show equivalent Young's modulus similar to commercial plates. However, produced plates containing six and eight holes ( $75 \%$ of volume reduction) show a significant reduction in the equivalent Young's modulus, presenting values in the cortical bone region, which is not possible to achieve with the commercially available plates. This confirms that topology optimization can be used to create lightweight plates (less material volume) with reduced equivalent stiffness and sufficiently strong without impairing the plate's mechanical performance, thus minimising the stress-shielding phenomena.

This study is limited in terms of considering the mechanical stability of the topology optimised bone plates, assuming that a significant decrease in the material volume could result in 


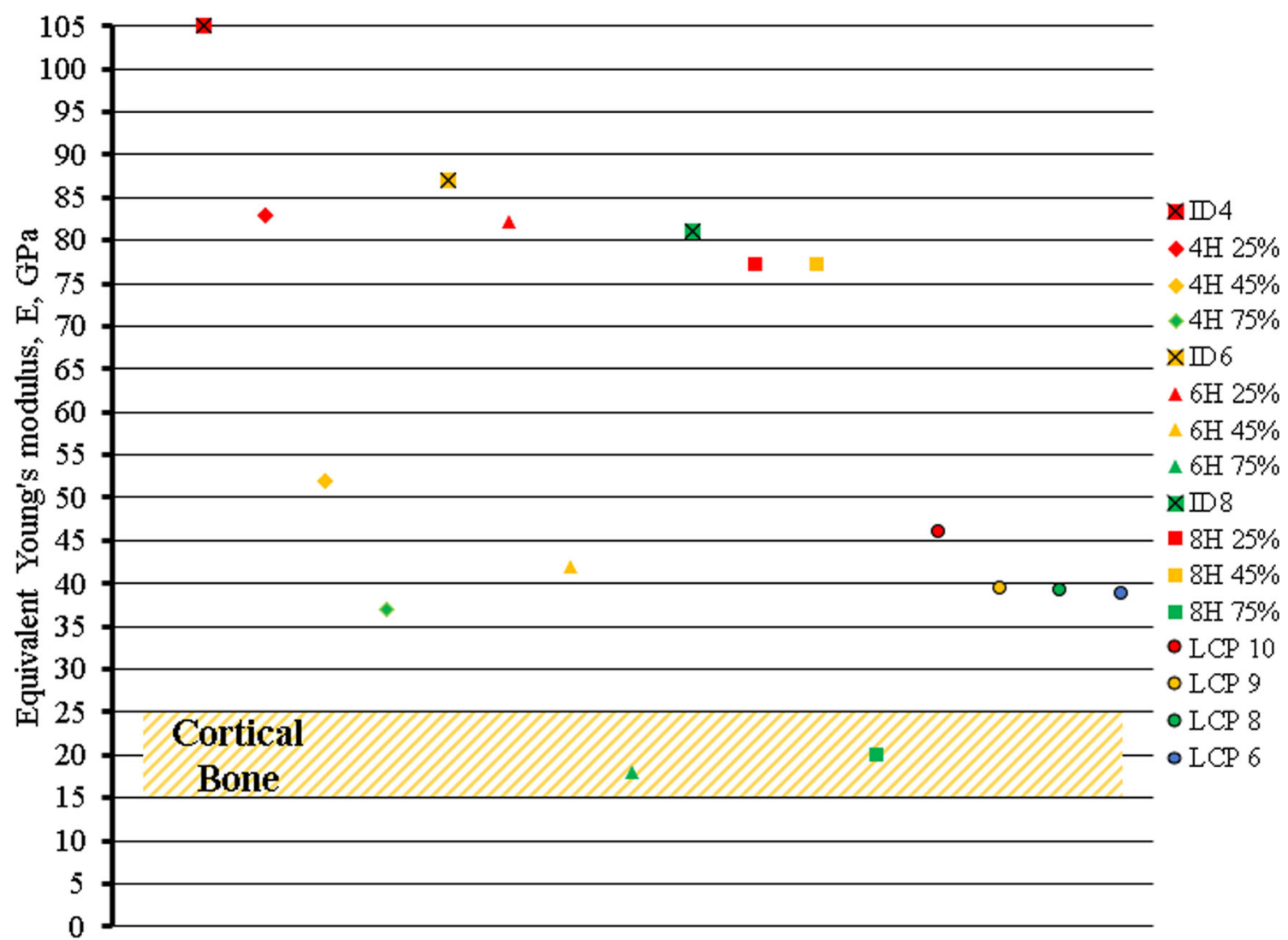

Fig. 9 Summary of the equivalent Young's modulus values for the considered commercial and EBM plates and their position with respect to the cortical bone. ID4: four-hole initial design; $4 \mathrm{H} 25 \%$ : four-hole $25 \%$ volume reduction; $4 \mathrm{H} 45 \%$ : four-hole $45 \%$ volume reduction; $4 \mathrm{H} 75 \%$ : four-hole $75 \%$ volume reduction; ID6: six-hole initial design; $6 \mathrm{H} 25 \%$ :

stress concentration and plate failure, leading to a delay of bone healing. However, the authors are addressing this limitation by analysing the plastic region of the mechanical tests, considering the commercial plate (i.e. DePuy Synthes LCP,

Table 2 Yield stresses of all bone plates

\begin{tabular}{lll}
\hline Plate & Volume reduction $(\%)$ & Yield stress (MPa) \\
\hline Four holes & Initial & 300 \\
& 25 & 281 \\
& 45 & 250 \\
Six holes & 75 & 160 \\
& Initial & 346 \\
& 25 & 200 \\
Eight holes & 45 & 91 \\
& 75 & 86 \\
& Initial & 368 \\
DePuy Synthes plate & 359 \\
\hline
\end{tabular}

six-hole $25 \%$ volume reduction; $6 \mathrm{H} 45 \%$ : six-hole $45 \%$ volume reduction; $6 \mathrm{H} 75 \%$ : six-hole $75 \%$ volume reduction; ID8: eight-hole

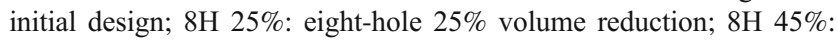
eight-hole $45 \%$ volume reduction; $8 \mathrm{H} 75 \%$ : eight-hole $75 \%$ volume reduction

the gold standard for bone fracture healing) as a reference to base the stability of the bone plates in terms of the yield stress results. Most of the bone plates presented a higher yield stress with two plates (four-hole $75 \%$ volume reduction and six-hole $25 \%$ volume reduction plates) showing similarity with the commercial ones in terms of yield behaviour. The resulting yield stresses for the two bone plates that have similar equivalent Young's modulus to the cortical bone showed approximately half of the commercial bone plate yield. However, if we consider that the maximum force required to yield the two bone plates are $4191 \mathrm{~N}$ (six holes and $75 \%$ of volume reduction) and $5481 \mathrm{~N}$ (eight hole and $75 \%$ of volume reduction), this is still clinically acceptable as it corresponds to 6 to 8 times the bodyweight of a 70-kg patient.

EBM-produced plates were not submitted to any postprocessing treatment (e.g. elimination of residual stresses, surface finishing and polishing). This was decided to avoid the use of any additional time, consumables and costly steps and to avoid any additional effects of the post-processing on the topography, microstructure and properties of the plates, partially answering the question: is it necessary to perform any post-processing to produce plates with adequate physical and 


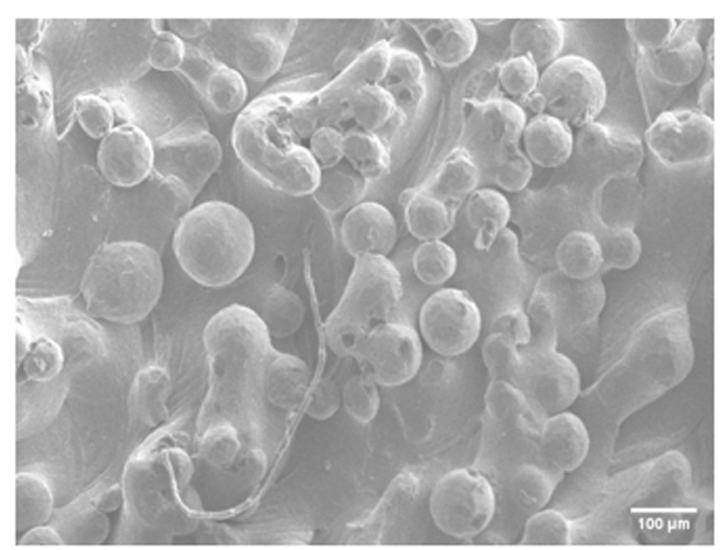

a)

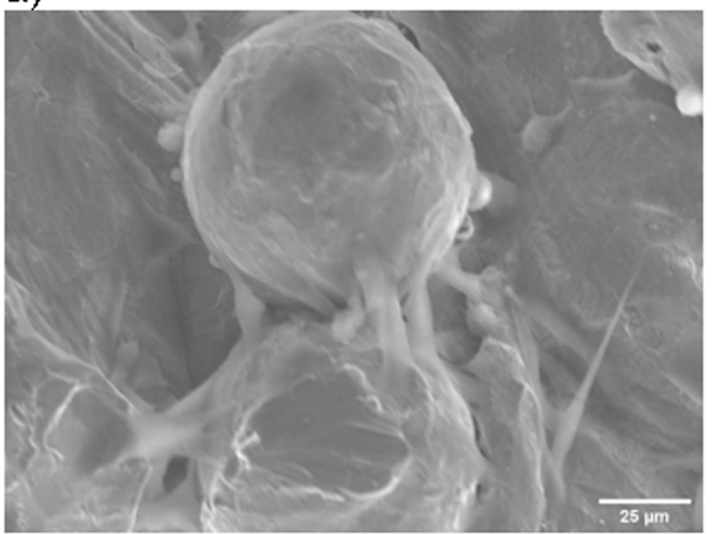

c)

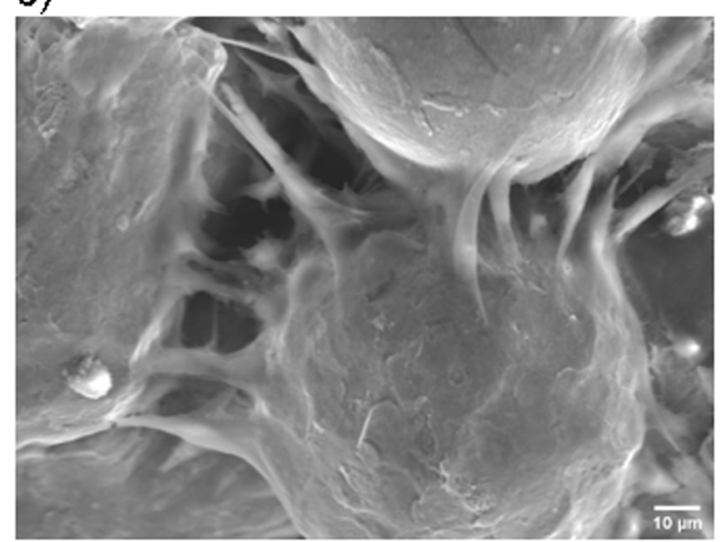

e)

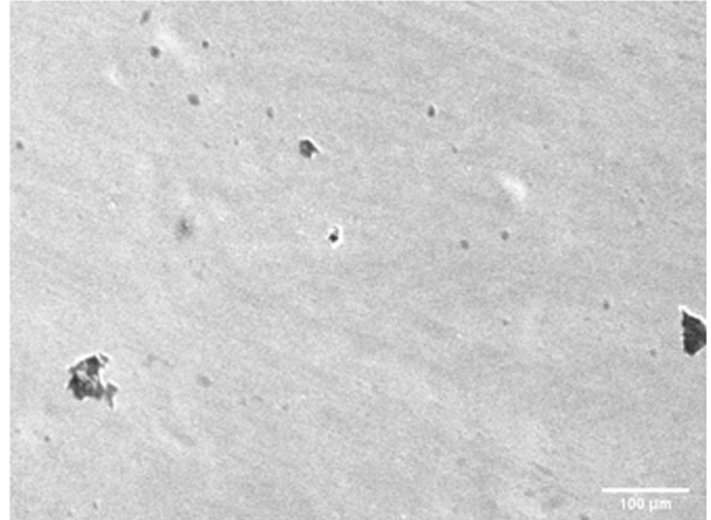

b)

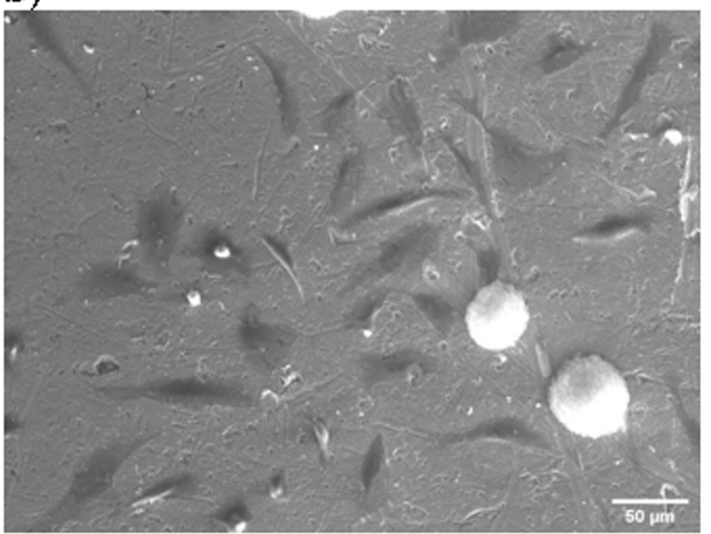

d)

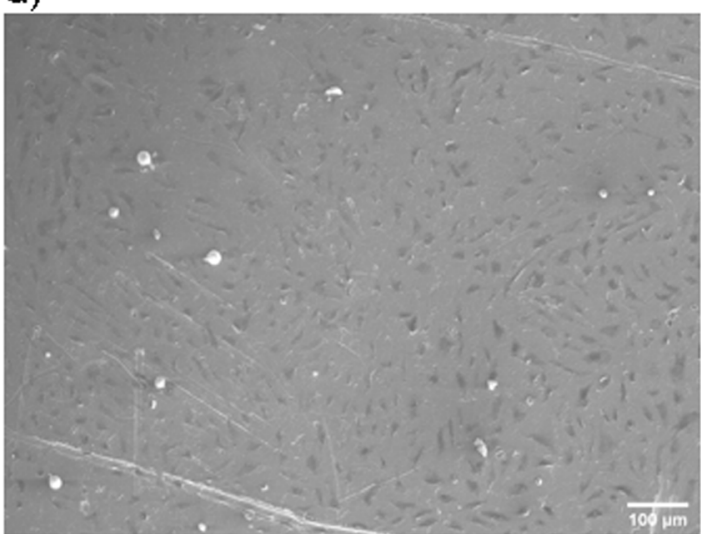

f)

Fig. 10 The SEM images before seeding of the surface topography of a EBM bone plate and $\mathbf{b}$ commercial bone plate. Cell morphology on $\mathbf{c}$ EBM after 7 days of cell culture, $\mathbf{d}$ commercial after 7 days of cell culture, e EBM after 14 days of cell culture and $\mathbf{f}$ commercial after 14 of cell culture

biological characteristics? Due to the nature of the EBM process (powder-bed fusion technique), rough parts were produced. As observed by Karlsson et al. [24] and Tong et al. [25], the surface characteristics of EBM parts are influenced by the raw powder characteristics (e.g. particle size) and processing conditions (e.g. scan speed) that result in the presence of both partially melted particles and fully melted ones (flattest zones aligned with the build direction). Despite presenting high surface roughness compared to commercial plates, produced plates were not polished to understand if the rough values were within an acceptable range to allow cell attachment and cell-cell communication. This was investigated by accessing the in vitro response of osteosarcoma cells seeded on both EBM and the commercial plates.

Contradictory results were previously reported regarding the biological influence of smooth and rough surfaces. According to De Wild et al. [26], EBM implants should be surface treated as their study showed improved biological response on acid-etched 


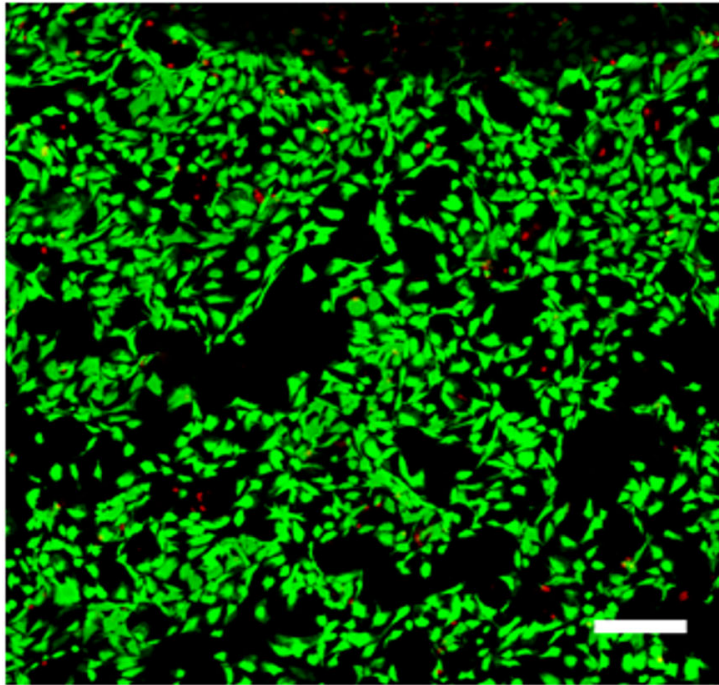

a)

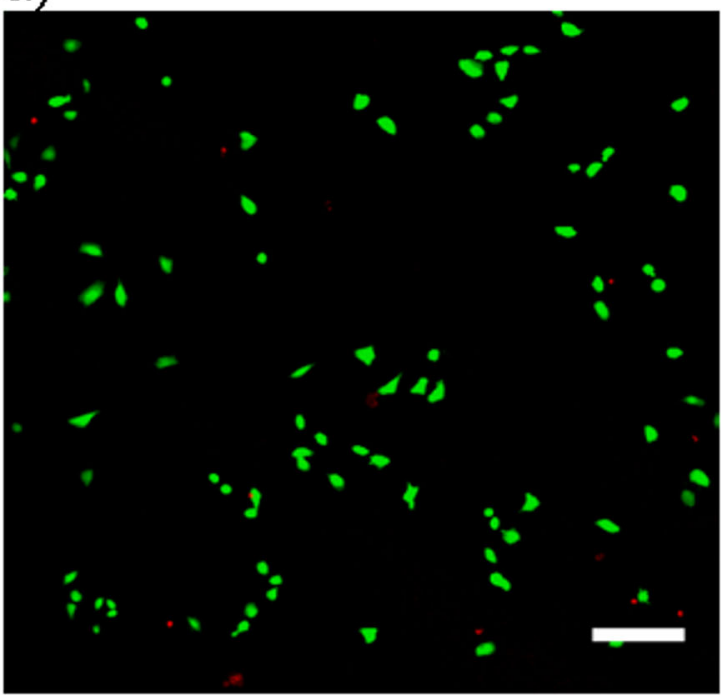

c)

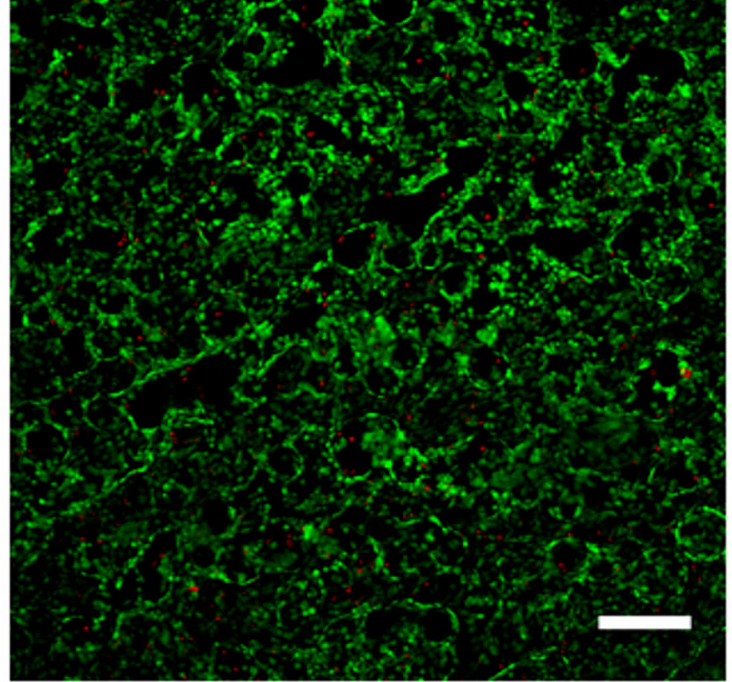

b)

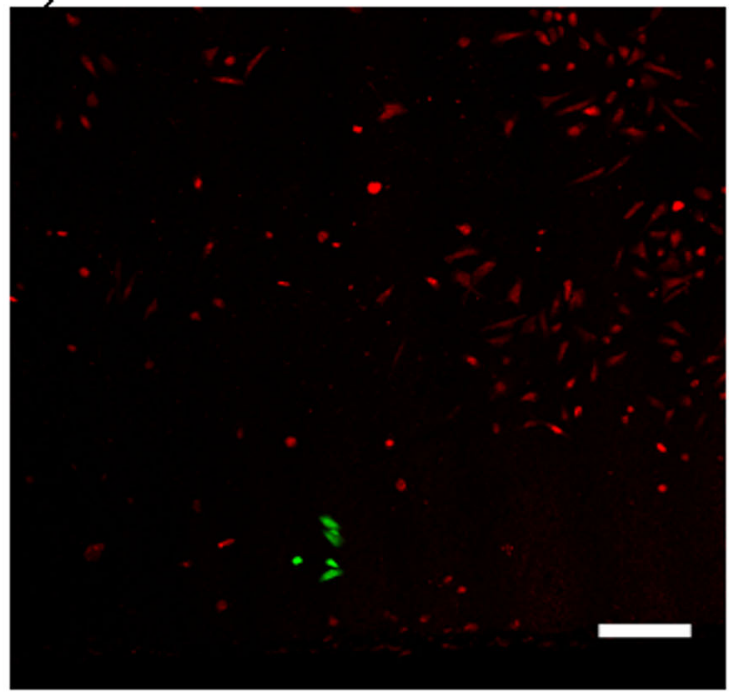

d)

Fig. 11 Cell viability images of the EBM a after day 4 and $\mathbf{b}$ after day 14 ; and $\mathbf{c}$ the commercial plates after day 4 and $\mathbf{d}$ day 14 , presenting red for dead cells and green for live cells. Scale bar $200 \mu \mathrm{m}$

and sand-blasted implants. Pattanayak et al. [27] showed that heat treated smoother implants improve the osteo-integration of the implants. However, Thomson et al. [28] and Bertollo et al. [29] did not observe significant differences between no postprocessed implants and conventionally wrought machined and plasma-sprayed implants. Ponader et al. [30] observed high cell attachment and proliferation in EBM parts with Ra values lower than $24.9 \mu \mathrm{m}$ and reduced cell proliferation values in rough parts (Ra higher than $56.9 \mu \mathrm{m}$ ), surprisingly showing that the highest proliferation rate and cell viability were obtained with highly smooth surfaces $\left(R_{\mathrm{a}}\right.$ of $\left.0.07 \mu \mathrm{m}\right)$. In contrast, the results presented in this paper showed that surface roughness of the produced plates $(19.15 \pm 1.56 \mu \mathrm{m})$ allowed a high level of cell attachment and proliferation suggesting that no polishing post-processing step is required after the plate printing phase. Results also show high cell attachment on the EBM rough plates than in the commercial plates with a smooth surface $(0.37 \pm 0.01 \mu \mathrm{m})$. Cell viability studies also show a significant number of dead cells in the commercial plates after 14 days of cell seeding compared to the EBM plates. This can be partially explained by the surface topography of the commercial bone plates. However, further investigation is required to elucidate the role that ion release and wettability have on cell interactions.

Surface hardness also has an important role on cell attachment and proliferation and differentiation. Several studies reported that harder substrates promote osteogenesis and increase cell attachment $[31,32]$. The results show that EBM plates present higher surface hardness $(326.9 \pm 3.35)$ than commercial plates $(275.98$ \pm 7.75 ), both exhibiting significantly higher values compared to cortical bone hardness (i.e. $\sim 50 \mathrm{HV}$ ) [33]. 


\section{Conclusion}

This paper presents an integrated strategy combining topology optimization and additive manufacturing to produce bone fixation plates minimising the stress-shielding phenomena. From the results, it is possible to conclude the following:

- Topology optimization can be used to design plates minimising the stress-shielding effect. For high values of volume reduction, the effect of material removal strongly contributes to an overall reduction of the equivalent stiffness of the designed bone fixation plates.

- Designed plates were successfully produced using EBM.

- No significant mechanical differences were observed between produced and designed, showing a good accuracy between numerical and experimental results. It was also possible to design plates with equivalent Young's modulus values in the region of cortical bone.

- No post-processing seems to be required to establish a good biological bonding with the surrounding tissue. High cell attachment and proliferation was observed on rough EBM plates, which also presents higher surface roughness than commercial plates. Contrary to other studies, results also show that EBM parts with no postprocessing present higher biocompatibility than commercially available plates.

Acknowledgements Authors are grateful for the support provided by the Saudi Arabian government, Manchester University Foundation Trust and Royal College of Surgeons of England. The first author is also grateful for the support of the Advanced Manufacturing Institute (AMI), King Saud University, Riyadh, Saudi Arabia. Mechanical tests were conducted with the support of the National Composites Certification and Evaluation Facility (NCCEF), University of Manchester, Manchester, UK.

Open Access This article is distributed under the terms of the Creative Commons Attribution 4.0 International License (http:// creativecommons.org/licenses/by/4.0/), which permits unrestricted use, distribution, and reproduction in any medium, provided you give appropriate credit to the original author(s) and the source, provide a link to the Creative Commons license, and indicate if changes were made.

\section{References}

1. Dorati R, Colonna C, Conti B (2011) Polymer scaffolds for bone tissue regeneration. In: Gefen A (ed) Studies in Mechanobiology, tissue Eng and biomater, 8th edn. Springer, pp 259-288

2. Lee J, Farag M, Park E et al (2014) A simultaneous process of 3D magnesium phosphate scaffold fabrication and bioactive substance loading for hard tissue regeneration. Mater Sci Eng C 36:252-260. https://doi.org/10.1016/j.msec.2013.12.007

3. Bigham-Sadegh A, Oryan A (2014) Basic concepts regarding fracture healing and the current options and future directions in managing bone fractures. Int Wound J 12:238-247. https://doi.org/10. 1111/iwj. 12231
4. Marsell R, Einhorn T (2011) The biology of fracture healing. Injury 42(6):551-555. https://doi.org/10.1016/j.injury.2011.03.031

5. Szypryt P, Forward D (2009) The use and abuse of locking plates. Orthop Trauma 23:281-290. https://doi.org/10.1016/j.mporth. 2009.07.002

6. Elias C, Lima J, Valiev R, Meyers M (2008) Biomedical applications of titanium and its alloys. JOM 60:46-49. https://doi.org/10. 1007/s11837-008-0031-1

7. Prasad K, Bazaka O, Chua M, Rochford M, Fedrick L, Spoor J, Symes R, Tieppo M, Collins C, Cao A, Markwell D, Ostrikov $\mathrm{K}(\mathrm{K})$, Bazaka K (2017) Metallic biomaterials: current challenges and opportunities. Mater 10:884. https://doi.org/10.3390/ ma10080884

8. Hanson B, van der Werken C, Stengel D (2008) Surgeons' beliefs and perceptions about removal of orthopaedic implants. BMC Musculoskelet Disord 9:73. https://doi.org/10.1186/1471-2474-973

9. McNamara L (2017) Bone as a material. In: Ducheyne P (ed) Comprehnsive biomaterials II, 2nd edn. Elsevier, Berlin, pp 202 227

10. Rho J, Tsui T, Pharr G (1997) Elastic properties of human cortical and trabecular lamellar bone measured by nanoindentation. Biomater 18:1325-1330. https://doi.org/10.1016/s0142-9612(97) 00073-2

11. Hofmann G (1992) Biodegradable implants in orthopaedic surgery - a review on the state-of-the-art. Clin Mater 10:75-80. https://doi.org/10.1016/0267-6605(92)90088-b

12. Inion (2015) Economic benefit of biodegradable ankle fracture fixation. 1-13. http://citeseerx.ist.psu.edu/viewdoc/download; jsessionid=86AC05BA59157E021E0BC92C3EDA3787?doi=10. 1.1.503.7636\&rep=rep $1 \&$ type $=$ pdf

13. Bartolo P, Kruth J, Silva J et al (2012) Biomedical production of implants by additive electro-chemical and physical processes. CIRP Ann 61:635-655. https://doi.org/10.1016/j.cirp.2012.05.005

14. Sing S, An J, Yeong W, Wiria F (2015) Laser and electron-beam powder-bed additive manufacturing of metallic implants: a review on processes, materials and designs. J Orthop Res 34:369-385. https://doi.org/10.1002/jor.23075

15. Anitha D, Das De S, Sun K et al (2013) Improving stability of locking compression plates through a design modification: a computational investigation. Comput Methods Biomech Biomed Eng 18:153-161. https://doi.org/10.1080/10255842.2013.785536

16. Bendsøe M (1989) Optimal shape design as a material distribution problem. Struct Optim 1:193-202. https://doi.org/10.1007/ BF01650949

17. Bendsøe M, Sigmund O (2004) Topology optimization. SpringerVerlag, Berlin Heidelberg

18. Kim S, Chang S, Son D (2011) Finite element analysis of the effect of bending stiffness and contact condition of composite bone plates with simple rectangular cross-section on the bio-mechanical behaviour of fractured long bones. Compos Part B Eng 42:1731-1738. https://doi.org/10.1016/j.compositesb.2011.03.001

19. Almeida H, Bártolo P (2014) Design of tissue engineering scaffolds based on hyperbolic surfaces: structural numerical evaluation. Med Eng Phys 36:1033-1040. https://doi.org/10.1016/j.medengphy. 2014.05.006

20. Denry I, Holloway J (2004) Elastic constants, Vickers hardness, and fracture toughness of fluorrichterite-based glass-ceramics. Dent Mater 20:213-219. https://doi.org/10.1016/s0109-5641(03)00094-0

21. Wang X, Xu S, Zhou S, Xu W, Leary M, Choong P, Qian M, Brandt M, Xie YM (2016) Topological design and additive manufacturing of porous metals for bone scaffolds and orthopaedic implants: a review. Biomater 83:121-141. https://doi.org/10.1016/j. biomaterials.2016.01.012

22. Sutradhar A, Park J, Carrau D, Nguyen TH, Miller MJ, Paulino GH (2016) Designing patient-specific 3D printed craniofacial implants 
using a novel topology optimization method. Med Biol Eng Comput 7:1123-1135. https://doi.org/10.1007/s11517-015-1418-0

23. Al-Tamimi A, Fernandes P, Peach C et al (2017) Metallic bone fixation implants: a novel design approach for reducing the stress shielding phenomenon. Virtual Phys Prototyp 12:141-151. https:// doi.org/10.1080/17452759.2017.1307769

24. Karlsson J, Snis A, Engqvist H, Lausmaa J (2013) Characterization and comparison of materials produced by electron beam melting (EBM) of two different Ti-6Al-4V powder fractions. J Mater Process Technol 213:2109-2118. https://doi.org/10.1016/j. jmatprotec.2013.06.010

25. Tong J, Bowen C, Persson J, Plummer A (2016) Mechanical properties of titanium-based Ti-6Al-4V alloys manufactured by powder bed additive manufacture. Mater Sci Technol 33:138-148. https:// doi.org/10.1080/02670836.2016.1172787

26. de Wild M, Schumacher R, Mayer K, Schkommodau E, Thoma D, Bredell M, Kruse Gujer A, Grätz KW, Weber FE (2013) Bone regeneration by the osteoconductivity of porous titanium implants manufactured by selective laser melting: a histological and micro computed tomography study in the rabbit. Tissue Eng A 19:26452654. https://doi.org/10.1089/ten.tea.2012.0753

27. Pattanayak D, Fukuda A, Matsushita T et al (2011) Bioactive Ti metal analogous to human cancellous bone: fabrication by selective laser melting and chemical treatments. Acta Biomater 7:13981406. https://doi.org/10.1016/j.actbio.2010.09.034

28. Thomsen P, Malmström J, Emanuelsson L, René M, Snis A (2008) Electron beam-melted, free-form-fabricated titanium alloy implants: material surface characterization and early bone response in rabbits. J Biomed Mater Res B Appl Biomater 90B:35-44. https://doi.org/10.1002/jbm.b.31250
29. Bertollo N, Da Assuncao R, Hancock N et al (2012) Influence of electron beam melting manufactured implants on ingrowth and shear strength in an ovine model. J Arthroplast 27:1429-1436. https://doi.org/10.1016/j.arth.2012.02.025

30. Ponader S, Vairaktaris E, Heinl P, Wilmowsky C, Rottmair A, Körner C, Singer RF, Holst S, Schlegel KA, Neukam FW, Nkenke E (2008) Effects of topographical surface modifications of electron beam melted Ti-6Al-4V titanium on human fetal osteoblasts. J Biomed Mater Res A 84A:1111-1119. https://doi.org/10. 1002/jbm.a.31540

31. Kuo Y, Hung S, Hsu S (2014) The effect of elastic biodegradable polyurethane electrospun nanofibers on the differentiation of mesenchymal stem cells. Colloids Surf B Biointerfaces 122:414-422. https://doi.org/10.1016/j.colsurfb.2014.07.017

32. Park J, Chu J, Tsou A et al (2011) The effect of matrix stiffness on the differentiation of mesenchymal stem cells in response to TGFß. Biomater 32:3921-3930. https://doi.org/10.1016/j.biomaterials. 2011.02.019

33. Evans G, Behiri J, Currey J, Bonfield W (1990) Microhardness and Young's modulus in cortical bone exhibiting a wide range of mineral volume fractions, and in a bone analogue. J Mater Sci Mater Med 1:38-43. https://doi.org/10.1007/bf00705352

Publisher's note Springer Nature remains neutral with regard to jurisdictional claims in published maps and institutional affiliations. 